\title{
Filtration Efficiency Improvement of Air Filter Paper for Fine Particles by Electrospinning Technology
}

\author{
Weiyin Su, Lanfeng Hui, * Xiaoyan Ma, Qian Yang and Wanhong Sun \\ Due to great advantages, such as simple operation, high porosity, and \\ good fiber continuity, the working principle and research progress of \\ electrospinning technology was studied and polyvinyl alcohol (PVOH) \\ nanofibers were prepared via this process. Air filter paper was used as the \\ receiving substrate to prepare electrospun nano air filter paper (NAFP). \\ The PVOH concentration, static voltage, and receiving distance, were \\ tested to explore the influence of spinning parameters on the filtration \\ performance. Further, the microfiber morphology of the electrospun NAFP \\ was observed. The performance of filter paper, including air permeability, \\ pore size, initial resistance, filtration efficiency, and dust retention, were \\ tested. The results showed that the electrospun NAFP had better filtration \\ performance compared to the air filter paper, and simultaneously they had \\ lower initial resistance and higher precision filtration efficiency. The \\ nanofiber influenced the surface of the air filter paper, as it sharply reduced \\ the pore size. When the spinning condition was $10 \%, 21 \mathrm{kV}$, and $15 \mathrm{~cm}$, \\ the pore size decreased approximately 0.6 times of the original, which \\ meant the electrospun NAFP could capture particles $\geq 0.2 \mu \mathrm{m}$ in size. \\ Finally, after three repeated uses, the good filtration performance was \\ maintained.
}

Keywords: Electrospinning; Nanofiber; Low resistance; High precision filtration efficiency; Reusability

Contact information: Tianjin Key Lab of Pulp \& Paper, Tianjin University of Science \& Technology, Tianjin 300457, China; *Corresponding author: huipeak@163.com

\section{INTRODUCTION}

In recent years, air quality has received increased attention. Lim et al. (2020) conducted a spatiotemporal derivation of the global $\mathrm{PM}_{2.5}$ concentration risk area from 1998 to 2016. Andreas et al. (2020) found that ambient air pollution caused by particulate matter (PM) and ozone was associated with up to 9 million all-cause deaths in 2015, most of which were due to brain and cardiovascular diseases, such as stroke and ischemic heart disease. Recent evidence suggests that exposure to air particles and gases can accelerate neurodegenerative diseases. Several studies have illustrated that the rapid development of urbanization necessitates higher requirements for air quality (Wang et al. 2021; Wu et al. 2021). Small-particle pollution has become increasingly serious, as toxic particles in the air can threaten human health. In recent years, $\mathrm{PM}_{2.5}$ has attracted much attention. This particle type has a small particle size, large specific surface area, strong activity, and a diameter $\leq 2.5 \mu \mathrm{m}$, and it easily attaches to toxic substances. It can be suspended in the air for a long time, which impacts human health and atmospheric environmental quality. As a medium, air filter paper is used to purify dust particles in the air. To better purify air and improve air quality, a novel technology called electrospinning technology is used to prepare a composite nano air filter paper with high filtration precision. In addition, the filter paper also has low filtration resistance. 
Electrospinning technology began 400 years ago, when Gilbert (the father of electromagnetic science) first found a smooth surface at a certain distance of the droplet and he tapered the droplets by friction (Tucker et al. 2012). This finding confirmed that there was liquid in the electric field due to the stress and deformation of the basic phenomena. The research of electrospinning technology peaked after the 1990s. At Akron University, Reneker et al. (Doshi and Reneker 1995; Srinivasan and Reneker 1995) conducted in-depth and extensive research on electrospinning technology. Since 2000, as new functional materials and nanofibers have been developed, countries around the world have shown great interest in this technology (Wang et al. 2017; Brabusamy et al. 2020; Xie et al. 2020). From the simplification of the preparation and characterization of nanofibers to the improved understanding of the forming process and mechanism of electrostatic spinning, electrospinning technology has substantially improved. It is a spinning method that makes charged polymer solution or its' melt flow and deform in the electrostatic field and then solidify by solvent evaporation or melt cooling, which ultimately results in nanofibers. Recently, researchers have learned more about electrospinning technology. Figure 1 illustrates how to flexibly use this technology. In addition, electrospinning nanofibers show great potential in many application fields. These nanofibers have been widely used in biomedicine, filter media, and protective clothing, and they have shown unique performance in the energy storage, sensor membrane, and reinforcement material fields (Geng et al. 2005; Barhate et al. 2006; Gopal et al. 2007; Fan et al. 2008).

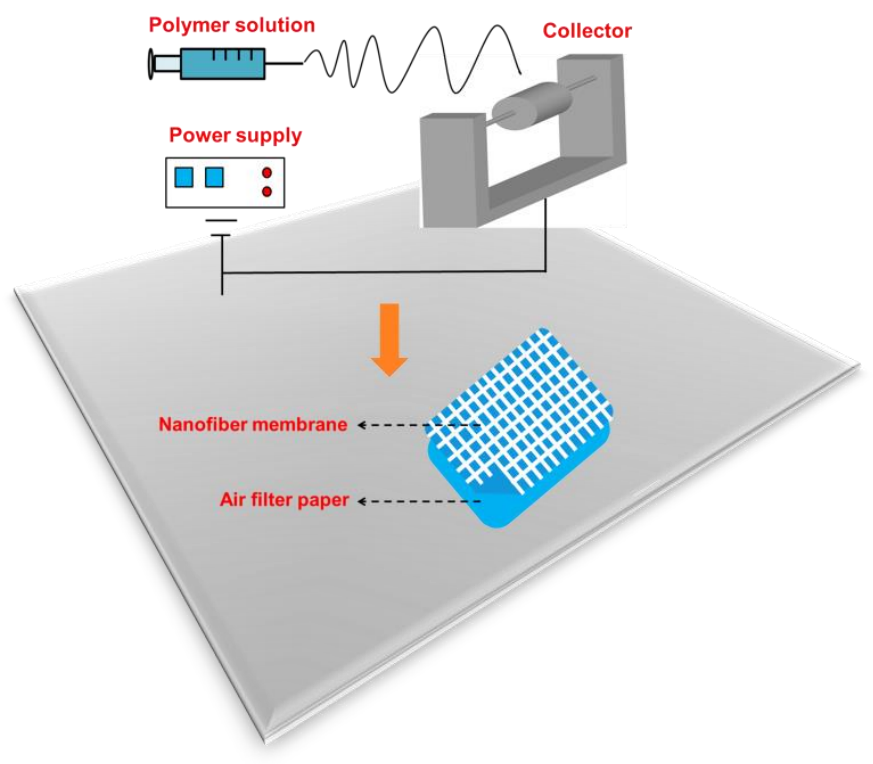

Fig. 1. Preparation process of NAFP

The polymer used in this experiment was polyvinyl alcohol (PVOH). Polyvinyl alcohol is a water-soluble and environmentally friendly polymer material that is obtained by alcoholysis after the polymerization of vinyl acetate. Due to its good mechanical properties, biocompatibility, barrier properties, and antistatic properties, $\mathrm{PVOH}$ is widely used in papermaking, adhesives, medicine, and other fields. The excellent properties of PVOH make it an important polymer in the electrospinning technology. El-Aziz et al. (2017) prepared continuously arranged $\mathrm{PVOH}$ nanofiber composites via the electrostatic spinning method, prepared $\mathrm{PVOH}$ and $\mathrm{PVOH} /$ hydroxyapatite nanofibers, and both of them 
crosslinked with glutaraldehyde (GA). A nanofiber membrane was prepared to remove $\mathrm{Zn}^{2+}$ from wastewater.

Air filter paper is used in home appliances to prevent small particles from causing harm to people. Filtration efficiency is one of the important indicators to detect the filtration performance of air filter paper. Figure 2 is the schematic of dust loading test setup. The most ideal situation is when the air filter paper can have both high filtration efficiency and large dust holding capacity under low initial resistance. In this paper, $\mathrm{PVOH}$ nanofibers were prepared via electrospinning technology, and air filter paper was used as the substrate. By deposition, the composite nanofibers were combined with air filter paper, and the composite nanofiber air filter paper (electrospun NAFP) was successfully prepared. The product had good characteristics, which included high filtration precision, relatively low filtration resistance, and high pollutant carrying capacity.

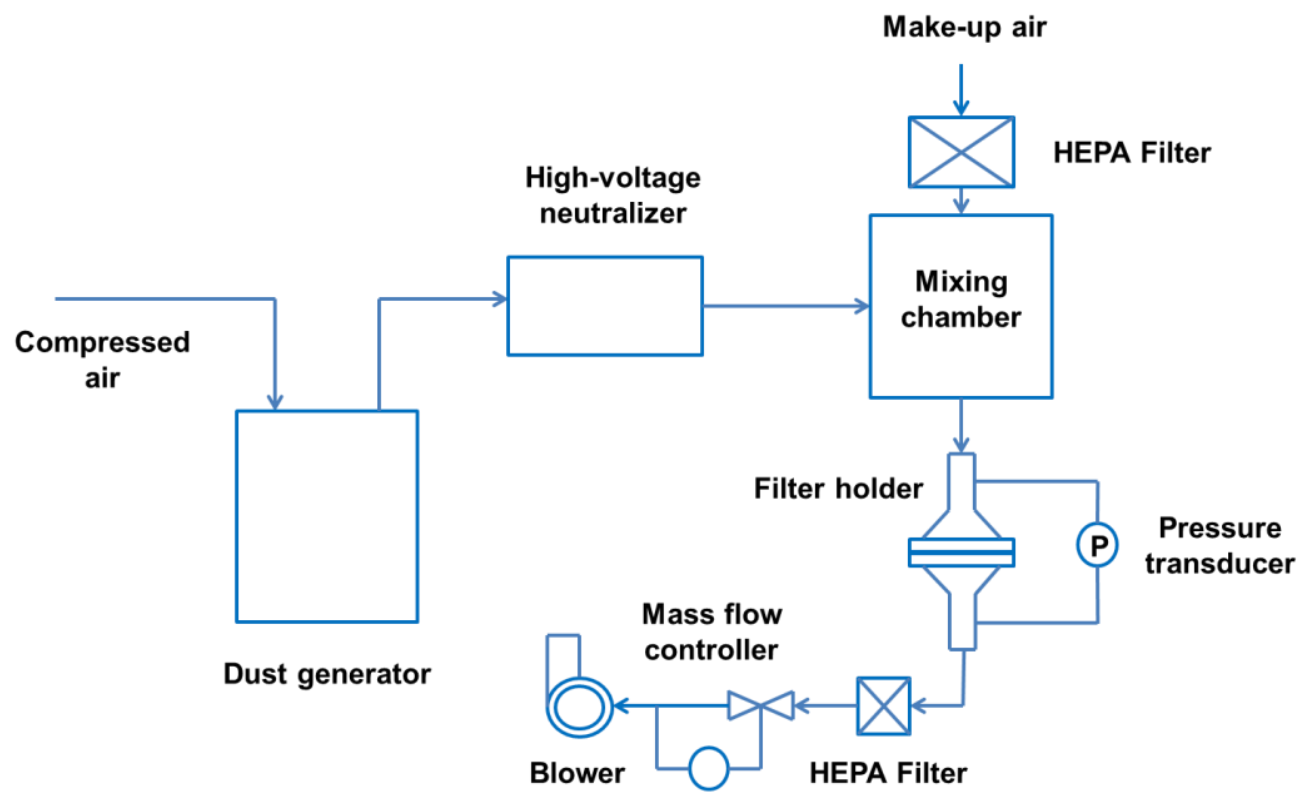

Fig. 2. A schematic diagram of the test rig

\section{EXPERIMENTAL}

\section{Preparation of PVOH Solution}

Several PVOH powders (Aladdin Industrial Corporation, Shanghai, China) of different masses were weighed in the beaker, deionized water was added, and the mixture was stirred on a thermal magnetic stirrer for $5 \mathrm{~h}$ to $6 \mathrm{~h}$ at $80^{\circ} \mathrm{C}$. Finally, the PVOH solutions with concentrations of $8 \%, 10 \%$, and $12 \%$ were prepared.

\section{Preparation of NAFP}

The prepared PVOH solutions of different concentrations were each injected into separate 10-mL syringes, and 22 needles were used. Then, the air filter paper was adhered to the roller with a PD30 electrospinning machine (Yunfan Instrument Co., Ltd., Tianjin, China). The rotation speed of the roller was set at $500 \mathrm{rpm}$, the pushing speed of the syringe was set at $0.56 \mathrm{~mL} / \mathrm{h}$, and the left and right moving speeds were both set to $15 \mathrm{~mm} / \mathrm{s}$. The voltage and receiving distance were changed without changing the above conditions. In 
this experiment, the PVOH nanofibers were deposited on the air filter paper via electrospinning technology. Finally, the filter paper was removed and dried in a DKM610C vacuum drying oven (Yamato, Shanghai, Japan) at $60{ }^{\circ} \mathrm{C}$ for $3 \mathrm{~min}$ to $5 \mathrm{~min}$.

\section{Characterization of Raw Material and Liquefaction Residues}

SEM analysis

After electrospinning, the air filter paper with PVOH deposited on the surface was cut into $1 \mathrm{~cm} \times 1 \mathrm{~cm}$ samples. After spraying with gold, the surface morphology of the samples was observed by a JSM-IT300LV scanning electron microscope (SEM) (Hitachi, Kanto, Japan).

\section{Air permeability test}

Air permeability can be defined as the degree to which the object or medium allows gas to pass through it. The value was determined by measuring the air permeability of the unit volume or section in unit time and specific pressure. The samples were placed in a YG461E digital air permeability meter (Ningbo Textile Factory, Ningbo, China). Under a pressure difference of $200 \mathrm{~Pa}$, the air flow through a given area of samples in a certain time was measured, and the air permeability was calculated.

\section{Pore size test}

Pore size was defined as the shape and size of pores in porous solids. The pores were irregular in shape. The pores were circle-shaped, and their radius was used to represent the size of the hole. A Porolux 100 FM capillary flow pore size analyzer (Promet NV Company, Antwerp, Belgium) was used to test the pore size of the filter paper. The special wetting solution was used to test the mean pore size of the filter paper.

\section{PALAS MFP3000 filter material test system analyses}

Filtration efficiency was defined as the ratio of the weight or quantity of particles captured by the filter to the weight or quantity of particles contained in the air before filtration, which was expressed as a percentage. The filtration efficiency was tested with an MFP3000 filter material test system (PALAS, Baden Wurttemberg, Germany). The dust used in the test was A2 standard dust (Shanghai Ruibei Trade Co., Ltd., Shaihai, China). In addition, the initial resistance and dust retention of the sample were also measured, and the two parameters interacted with each other. The dust retention was defined as the dust holding capacity of the samples. The dust capacity was related to the service life of the samples (Sun et al. 2018).

\section{RESULTS AND DISCUSSION}

\section{Performance Analysis of NAFP}

Electrostatic spinning was mainly affected by the concentration of the polymer solution, spinning voltage, and acceptance distance. The diameters of the PVOH nanofibers after electrospinning are shown in Fig. 3, and they were between 0.26 and $0.40 \mu \mathrm{m}$. The test results under different spinning conditions are shown in Fig. 4. SEM results showed the morphology of electrospun NAFP fiber. The results for $0 \% \mathrm{PVOH}$ concentration represent the fiber morphology of the original air filter paper. Before electrostatic spinning, the fiber diameter was large, and the distribution was loose. In addition, the fibers 
interlaced with each other irregularly, and the pores between the fibers differed in size (Teo and Ramakrishna 2006). The surface of the electrospun NAFP prepared via the electrostatic spinning method was covered by a thin fiber film, which consisted of interlaced nanofibers. Concentration had the most notable effect on fiber morphology. Figure 4(a-2) shows that the nanofiber membrane reduced the permeability of the filter paper. When the PVOH concentrations were $8 \%$ and $10 \%$, the fiber morphologies were good. Further, the air permeability was lowest at $10 \%$, whereas the fiber exhibited an obvious bending phenomenon when PVOH concentration was 12\% (Frenot and Chronakis 2003; Reneker et al. 2007; Zdanowski and Kędzia 2007). If the PVOH concentration was too low or too high, the viscosity and charge density of the solution would be too small or too large, and the viscoelasticity and surface tension would be too small or too large, which would affect the splitting ability of the solution. When the surface tension and electrostatic force of the solution reached equilibrium, a Taylor cone could be formed, and spinning could be carried out continuously and stably (Bhardwaj and Kundu 2010). Figures 4(a-3) and 4(a-4) show that the pore size and dust retention of NAFP decreased initially and then increased, whereas the filtration efficiency and resistance increased initially and then decreased. However, compared with the base paper, the pore size and dust retention of the electrospun NAFP always decreased, whereas the filtration efficiency and resistance increased. The size of the pores indirectly affected the filtration efficiency. Nanofibers divided the large pores of the original air filter paper into multiple small pores. When dust particles moved from upstream to downstream, more small-sized dust was intercepted due to the reduction of pore sizes. The filtering efficiency was calculated as shown in Formula (1):

$$
P(\%)=W_{\mathrm{u}} /\left(W_{\mathrm{u}}+W_{\mathrm{d}}\right)
$$

In this expression, $W_{\mathrm{u}}$ is the weight of upstream dust and the $W_{\mathrm{d}}$ is the weight of downstream.

As the driving force of the electrospinning process, voltage played an important role in the process of electrostatic spinning (Spivak et al. 2000; Liang et al. 2019; Tian et al. 2019). Figure 4(b-1) shows that when the voltage was $15 \mathrm{kV}$, there were few fibers, and the cross pores between the fibers were large. The voltage was affected by the charge density of the jet passing through the electric field, which affected the electrospinning effect. When the voltage was $21 \mathrm{kV}$, from Fig. 4(b-2) through 4(b-4), the air permeability and resistance were the lowest value and filtration efficiency was the highest value. The fibers were arranged in the most compact way. Though the increase in electrostatic repulsion of jet surface charge was conducive to the formation of fine fibers, the increase of the velocity of air flow leaving the nozzle led to the instability of fine air flow; thus, the spinning results were further affected. As the air permeability of electrospun NAFP decreased, the pore sizes decreased and the resistance increased, which led to higher filtration efficiency and reduced dust retention. Large particles exhibited inertial motions, small particles exhibited diffuse motions, and some exhibited irregular motions. When the pore size was reduced, the airflow would bypass the nanofibers covering the surface and pass through the pores during the test. But at the same time, the increase in the number of fibers also increased the contact area through the airflow, which intensified the collision between the airflow and the fibers, resulting in an increase in the pressure drop on the surface of the filter paper. The receiving distance mainly affected the fiber morphology by changing the electric field intensity (Zhang et al. 2017). Figure 4(c-1) shows that when the receiving distances were 12 and $20 \mathrm{~cm}$, the fiber distributions were uneven and exhibited obvious bending phenomena. 


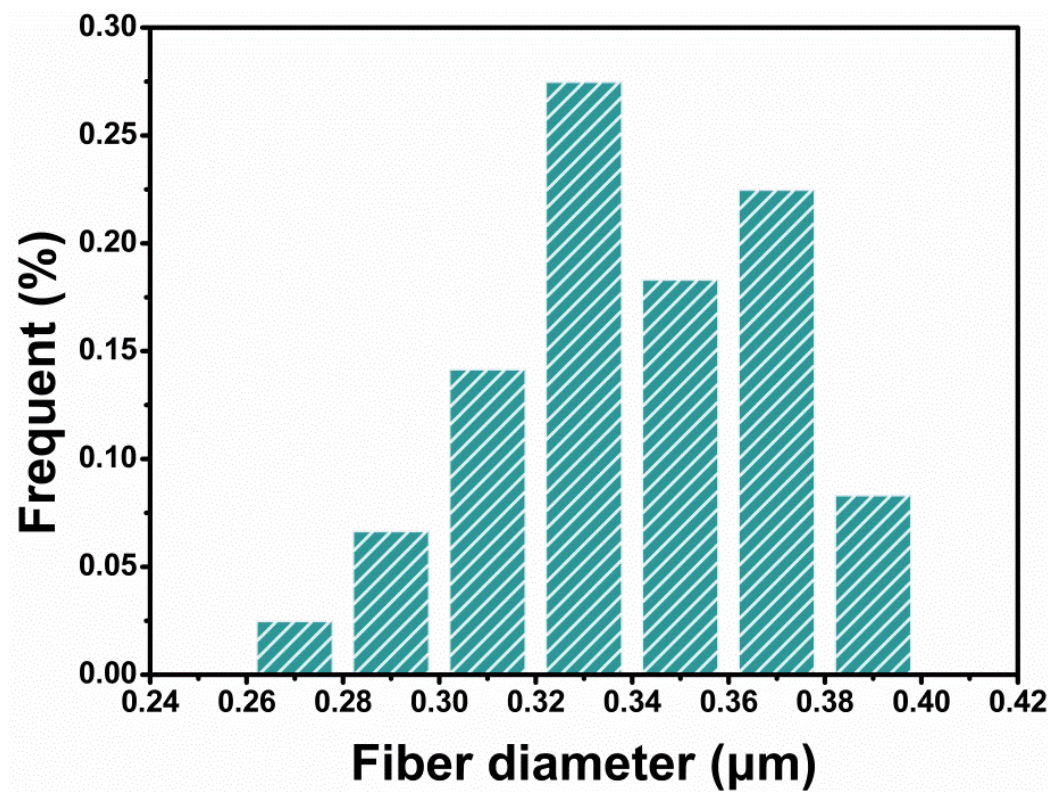

Fig. 3. Average diameter distribution of nanofibers

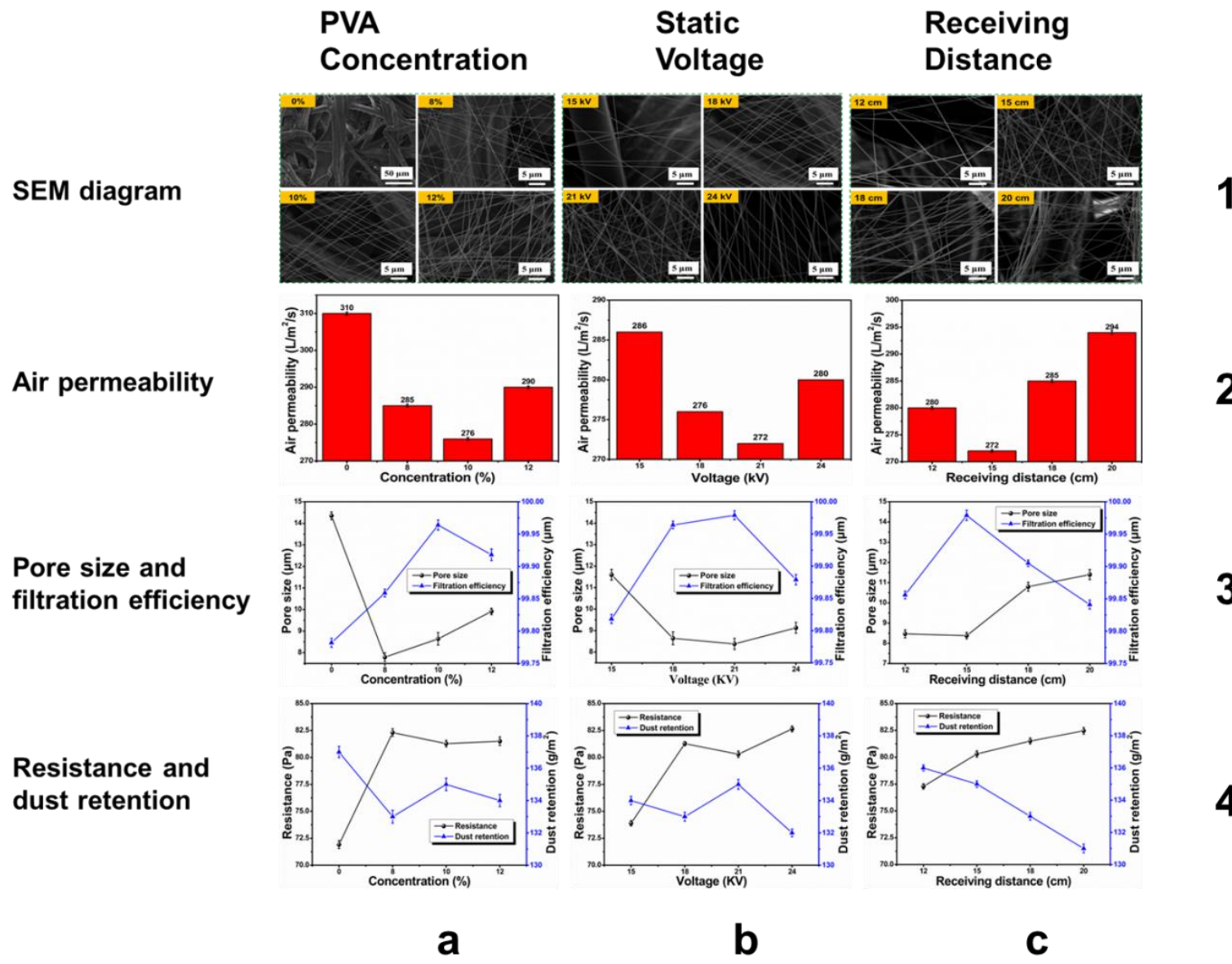

Fig. 4. Characteristic chart analysis of electrospun NAFP under different conditions

When the receiving distance was $18 \mathrm{~cm}$, the fiber distribution was loose. When the receiving distance was $15 \mathrm{~cm}$, the fibers were closely arranged, and the pores between the 
fibers were relatively small. In the electric field, small flow was formed by electrostatic force. When the receiving distance was short, the residence time of small flow in the electric field was also short, then the splitting frequency was reduced and the tension was insufficient, which resulted in incomplete solvent volatilization and adhesion of the fibers to the receiving plate (Hassan and Anke 2020). As the receiving distance increased, the diameter of the obtained fiber became relatively uniform, and the surface was smooth and level. With different receiving distances, Fig. 4(c-2) shows the air permeability analysis diagram, Fig. 4(c-3) shows the pore size and filtration efficiency analysis diagram, and Fig. 4(c-4) shows the resistance and dust retention analysis diagram. The change of these characteristics was similar to that of static voltage.

\section{Analysis of Pore Size and Filtration Efficiency for Electrospun NAFPs}

When measuring the pore size, the wetting liquid (isopropyl alcohol) was bound between the pores, and pressure was applied to one side of the paper. With the constant increase in gas pressure, the wetting liquid in the pores was extruded by the gas until the gas pressure increased beyond the pressure generated by the surface tension in the wetting liquid within a certain pore size. Figure 5 shows that the pore size of electrospun NAFPs $(10 \%$ PVOH solution, $21 \mathrm{kV}, 15 \mathrm{~cm}$ ) changed as the pressure increased. As the pressure increased, the pore size gradually decreased. This result occurred because, as pore size declined, the pressure generated by the surface tension of the paper increased, and the gas pressure required for pushing out the wetting solution increased. Figure 6 shows the flow distribution of electrospun NAFPs pores with different sizes. Figure 6 shows that that the distributions of pores between $5.45 \mu \mathrm{m}$ and $9.52 \mu \mathrm{m}$ were more concentrated. Among them, $6.10 \mu \mathrm{m}$ was the most concentrated, which indicated that the nanofibers on the surface of electrospun NAFPs prepared by electrospinning were relatively uniform; thus, the surface was conducive to improving the filtration efficiency of filter paper (Japuntich et al. 1997; Zhao 2006).

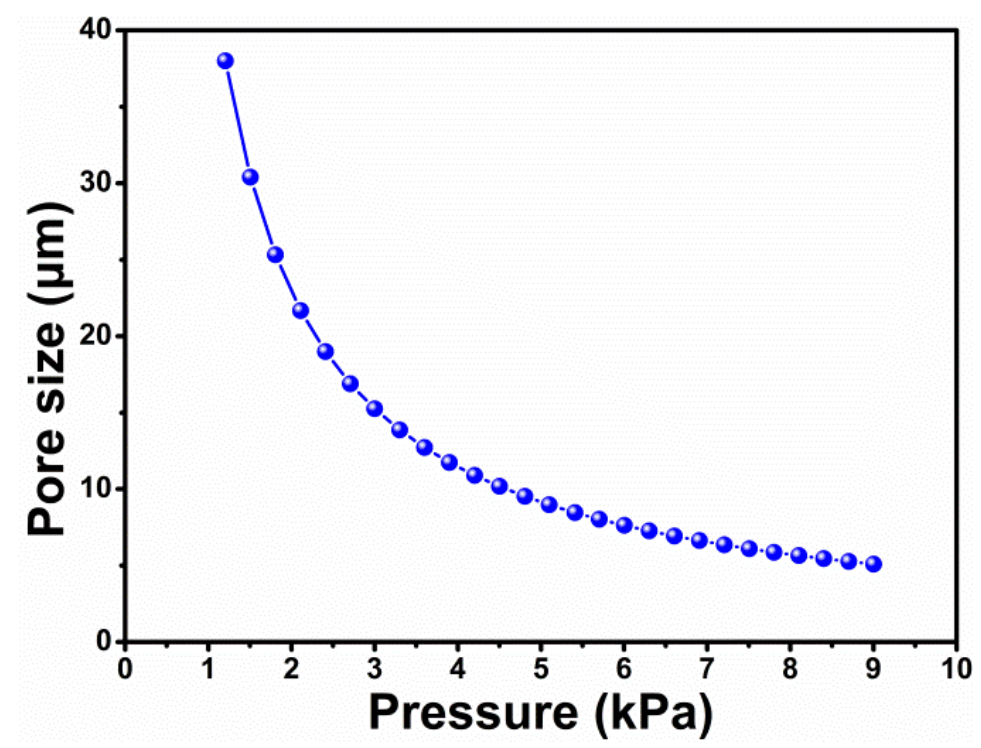

Fig. 5. Analysis of pore size variation with the pressure of electrospun NAFPs 


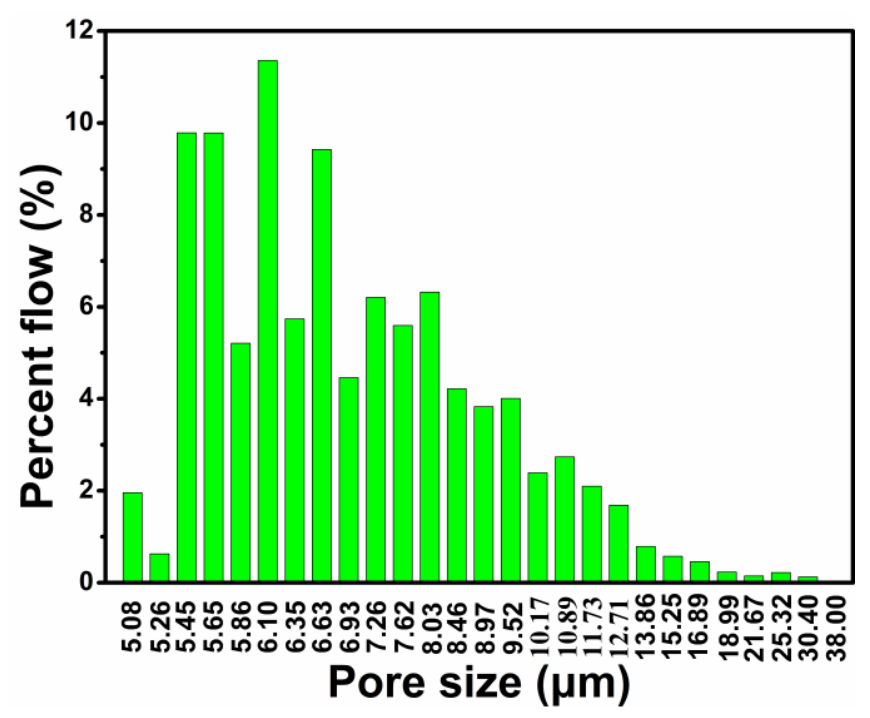

Fig. 6. Percentage flow analysis of the different pore sizes of electrospun NAFPs

The test results with the resistance of $118 \mathrm{~Pa}$ are shown in Fig. 7. The black curve represents the original filter paper's filtration efficiency, and the blue curve shows the electrospun NAFPs' filtration efficiency. As the dust particle size increased, filtration efficiency gradually decreased. The filtration efficiency of electrospun NAFPs with dust particles $\leq 2.0 \mu \mathrm{m}$ in size increased remarkably (up to 3.4 times the original filter paper). However, the filtration efficiency of dust particles $\geq 2.0 \mu \mathrm{m}$ did not.

The high efficiency air filter (HEPA) was mainly used to catch particle dust $>0.5$ $\mu \mathrm{m}$ in size. The basic requirements are high filtration efficiency and low resistance to allow continuous, long-term use to reduce costs. Figure 8 shows the analysis of electrospun NAFPs filtered particles smaller than $0.5 \mu \mathrm{m}$. The electrospun NAFPs maintained high filtration efficiency for particles of up to $0.5 \mu \mathrm{m}$. Compared to HAPE, electrospun NAFPs could filter smaller particles. As shown in Table 1, the initial resistance of electrospun NAFPs increased by $8.38 \mathrm{~Pa}$, and the air permeability decreased $38 \mathrm{~L} / \mathrm{m}^{2} / \mathrm{s}$. In general, electrospun NAFPs had high filtration efficiency, low initial resistance, and low PVOH cost.

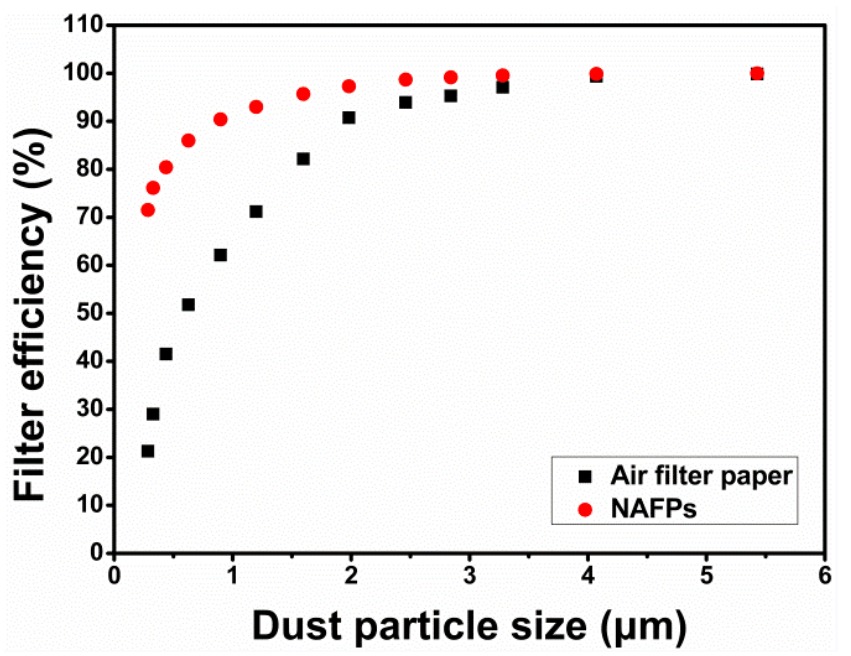

Fig. 7. Analysis of the filtration efficiency of different electrospun NAFPs dust particle sizes 


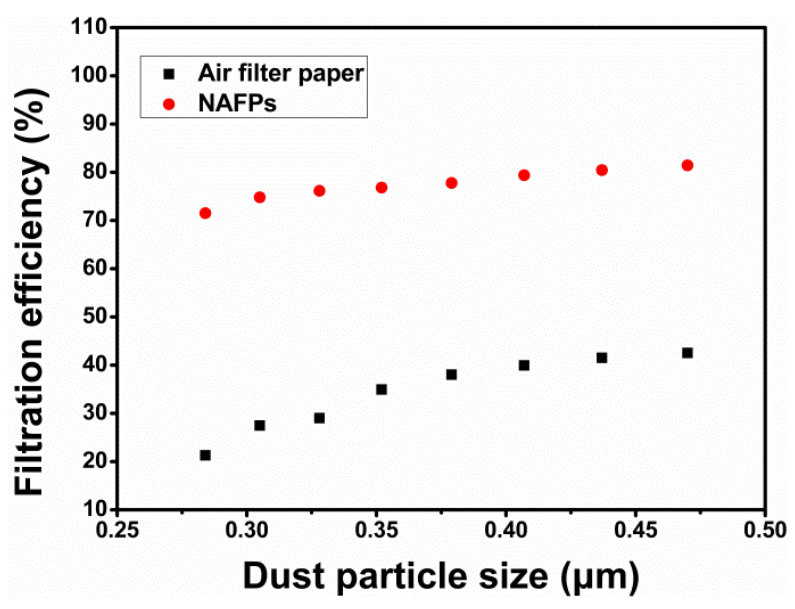

Fig. 8. Analysis of the electrospun NAFPs filtered particles smaller than $0.5 \mu \mathrm{m}$

Table 1. Basic Properties of Air Filter Paper and Electrospun NAFPs

\begin{tabular}{|c|c|c|c|c|}
\hline & $\begin{array}{c}\text { Initial } \\
\text { Resistance } \\
(\mathbf{P a})\end{array}$ & $\begin{array}{c}\text { Filtration } \\
\text { Efficiency } \\
(\%)\end{array}$ & $\begin{array}{c}\text { Dust } \\
\text { Retention } \\
\left(\mathbf{g} / \mathbf{m}^{2}\right)\end{array}$ & $\begin{array}{c}\text { Air } \\
\text { Permeability } \\
\left(\mathbf{L} / \mathbf{m}^{2} / \mathbf{s}\right)\end{array}$ \\
\hline Air Filter Paper & 71.92 & 99.782 & 137 & 310 \\
\hline $\begin{array}{c}\text { Electrospun } \\
\text { NAFPs }\end{array}$ & 80.30 & 99.979 & 135 & 272 \\
\hline
\end{tabular}

The improvement in the filtration efficiency of the electrospun NAFPs was attributed to the PVOH nanofiber membrane covering the surface of the filter paper as mentioned above. In addition, the thin $\mathrm{PVOH}$ membrane increased the initial resistance of the filter paper from 71.92 to $80.30 \mathrm{~Pa}$ (Japuntich et al. 1994; Podgórski et al. 2006; Lee et al. 2008; Hasolli et al. 2013). During the PALAS test, the final results were obtained by increasing the pressure difference by 500, 1000, and $2000 \mathrm{~Pa}$ in turn. Figure 9 shows the line charts of the resistance and dust retention of the air filter paper and electrospun NAFPs over time.

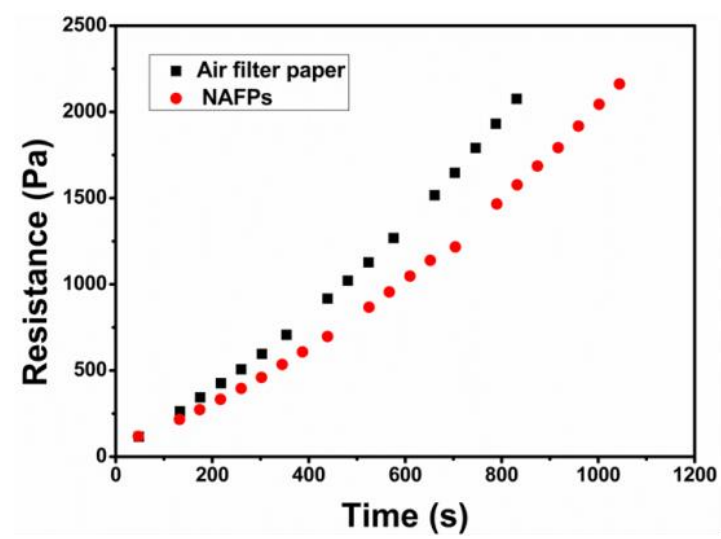

a

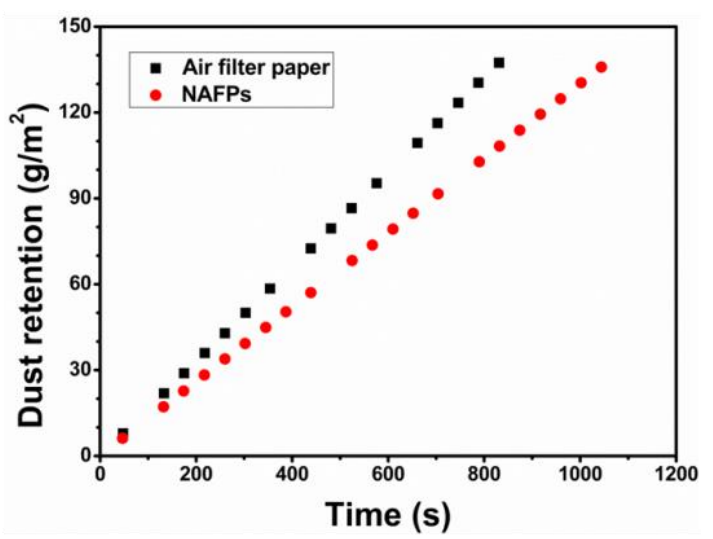

b

Fig. 9. Analysis of resistance and dust retention 
The air filter paper finished the test at $831 \mathrm{~s}$, the dust retention was $137 \mathrm{~g} / \mathrm{m}^{2}$, and the resistance and dust retention of the electrospun NAFPs were slowly increasing. The test time of the NAFPs took $1044 \mathrm{~s}$, and the dust retention was $135 \mathrm{~g} / \mathrm{m}^{2}$. This was because the PVOH membrane on the electrospun NAFPs increased the initial resistance, further increased the filtration hindrance of the particles, and prolonged the filtration time. However, due to the great improvement in the filtration efficiency of small particles, the dust retention of electrospun NAFPs decreased little, which meant that the electrospun NAFPs had a good filtration effect.

After the filtration efficiency test of the electrospun NAFPs, the dust on the surface was blown off with an air pressure gun, and the filter paper was measured again after back blowing. After the test, the experiment was repeated. The electrospun NAFPs was measured 3 times, and the results are shown in Figs. 10 and 11. Figure 10 shows the initial resistance histogram of the electrospun NAFPs after three measurements. The resistance increased from 80.30 to $101.45 \mathrm{~Pa}$ in increments of approximately $10 \mathrm{~Pa}$. Figure 11 is a broken line chart of the filtration efficiency of the electrospun NAFPs after three measurements. The three curves were all increasing. The results showed that the filtration efficiency of the electrospun NAFPs increased the most after the first measurement, followed by the second measurement, and the filtration efficiency of the electrospun NAFPs increased the least after the third measurement. There were two reasons for this result. First, though most of the dust was blown off, several small particles remained on the surface of the electrospun NAFPs because of the viscosity of the PVOH, and a dust and $\mathrm{PVOH}$ nanofiber membrane was formed. This resulted in increased initial resistance and filter blocking effect of the electrospun NAFPs, and filtration efficiency decreased. Secondly, a small part of dust was stuck in the gap between the PVOH nanofiber membrane, which reduced the number of open pores in the electrospun NAFPs and decreased the filtration efficiency.

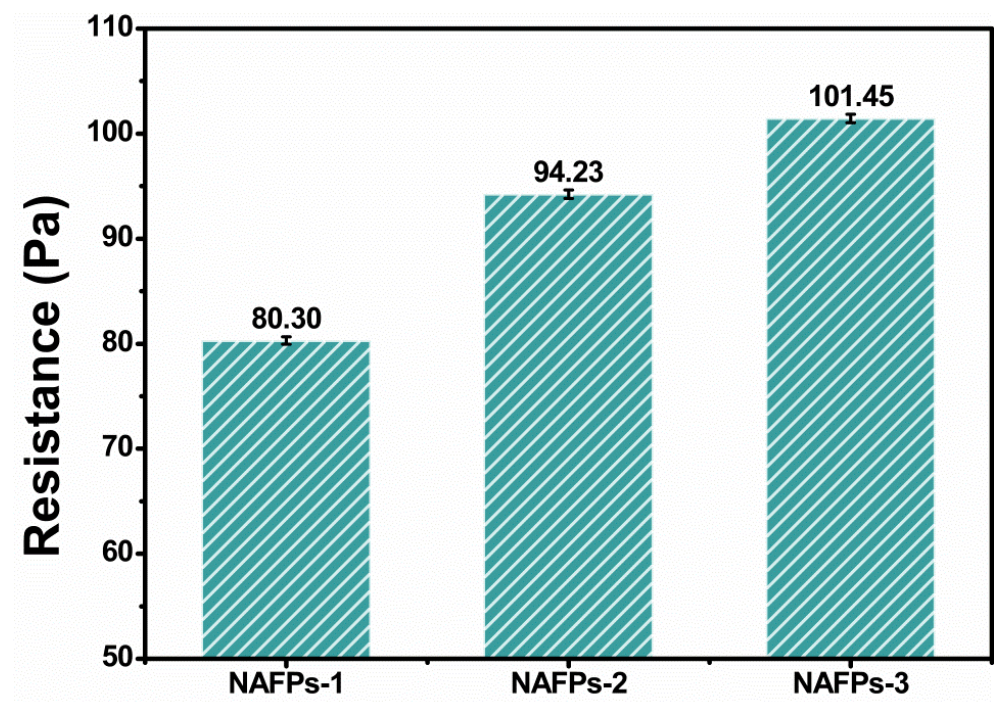

Fig. 10. Analysis of resistance changes after three measurements of the electrospun NAFPs Note: NAFPs-1, NAFPs-2, and NAFPs-3 represent the electrospun NAFP after the first, second, and third tests, respectively 


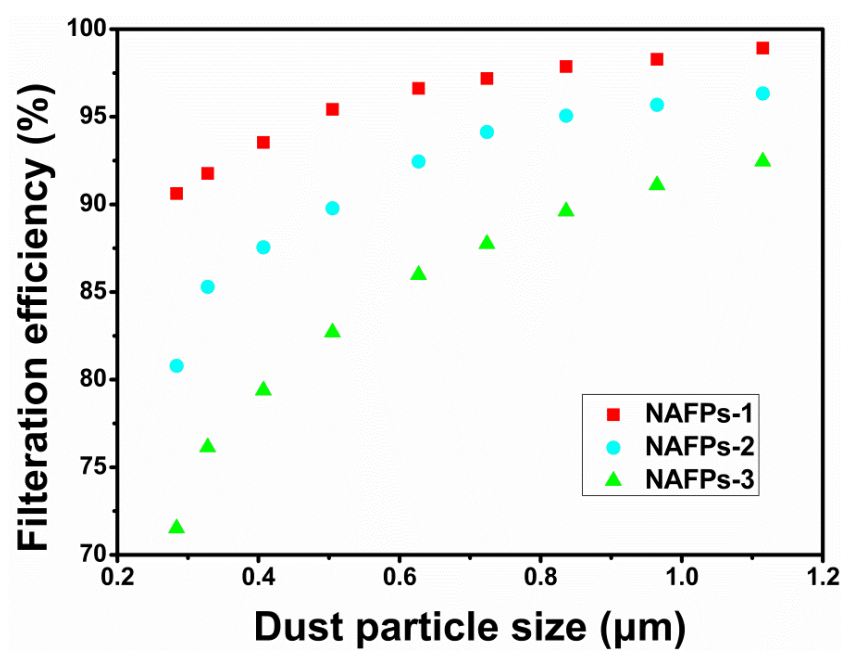

Fig. 11. Analysis of the filtration efficiency after three measurements of the electrospun NAFPs Note: NAFPs-1, NAFPs-2, and NAFPs-3 represent the electrospun NAFP after the first, second, and third tests, respectively

The electrospun NAFPs prepared by electrostatic spinning could noticeably improve the particle size of small-sized particles, and the electrospun NAFPs had good reusability. Though the initial resistance increased and the filtration efficiency decreased, it was better than the original air filter paper.

\section{CONCLUSIONS}

1. In this paper, via using the electrospinning technology, the nanofibers prepared by spinning were combined with the air filter paper. The resulting novel electrospun nano air filter paper remarkably improved the filtration accuracy.

2. The preparation of polyvinyl alcohol (PVOH) nanofibers by electrostatic spinning was mainly affected by solution concentration, spinning voltage, and receiving distance, which further affected the structural properties of electrospun NAFP.

3. The electrospun NAFP greatly reduced the pore size and improved the filtration efficiency of the original paper. In particular, the filtration efficiency of electrospun NAFP was remarkably higher than that of the original (3.4 times) for particles smaller than $2.0 \mu \mathrm{m}$.

4. The nanofiber film combined with the surface of the filter paper increased the resistance and decreased the air permeability. After repeated testing, the resistance of electrospun NAFP gradually increased, and the filtration efficiency gradually decreased, which meant that the filter paper was reusable in practical applications.

\section{ACKNOWLEDGMENTS}

This project was financially supported by the National Key Research and Development Plan (Grant No. 2017YFB0308300) and the National Nature Science Foundation of China (NSFC; No.21576213). 


\section{REFERENCES CITED}

Andreas, D., Marin, K., Omar, H., Lucia, G. D., Susanne, R., Fabio, D. L., Rainer, S., and Thomas, M. (2020). "Effects of air pollution particles (ultrafine and fine particulate matter) on mitochondrial function and oxidative stress - Implications for cardiovascular and neurodegenerative diseases," Archives of Biochemistry and Biophysics 696(15), Article ID 108662. DOI: 10.1016/j.abb.2020.108662

Bhardwaj, N., and Kundu, S. C. (2010). "Electrospinning: A fascinating fiber fabrication technique," Biotechnology Advances 28(3), 325-347. DOI:

10.1016/j.biotechadv.2010.01.004

Barhate, R. S., Long, C. K., and Ramakrishna, S. (2006). "Preparation and characterization of nanofibrous filtering media," Journal of Membrane Science 283(1-2), 209-218. DOI: 10.1016/j.memsci.2006.06.030

Brabusamy, B., Celebioglu, A., Senthamizhan, A., and Uyar, T. (2020). "Progress in the design and development of "fast-dissolving" electrospun nanofibers based drug delivery systems - A systematic review," Journal of Controlled Release 326, 482509. DOI: 10.1016/j.jconrel.2020.07.038

Doshi, J., and Reneker, D. H. (1995). "Electrospinning process and applications of electrospun fibers," Journal of Electrostatics 35(2-3), 151-160. DOI: 10.1016/03043886(95)00041-8

El-aziz, A. M. A., El-Maghraby, A., and Taha, N. A. (2017). "Comparison between polyvinyl alcohol (PVOH) nanofiber and polyvinyl alcohol (PVOH) nanofiber/hydroxyapatite (HA) for removal of $\mathrm{Zn}^{2+}$ ions from wastewater," Arabian Journal of Chemistry 10(8), 1052-1060. DOI: 10.1016/j.arabjc.2016.09.025

Fan, Z., Wang, Z., Duan, M., Wang, J., and Wang, S. (2008). "Preparation and characterization of polyaniline/polysulfone nanocomposite ultrafiltration membrane," Journal of Membrane Science 310(1-2), 402-408. DOI:

10.1016/j.memsci.2007.11.012

Frenot, A., and Chronakis, I. S. (2003). "Polymer nanofibers assembled by electrospinning," Current Opinion in Colloid \& Interface Science 8(1), 64-75. DOI: 10.1016/S1359-0294(03)00004-9

Geng, X., Kwon, O.-H., and Jang, J. (2005). "Electrospinning of chitosan dissolved in concentrated acetic acid solution," Biomaterials 26(27), 5427-5432. DOI:

10.1016/j.biomaterials.2005.01.066

Gopal, R., Kaur, S., Feng, C. Y., Chan, C., Ramakrishna, S., Tabe, S., and Matsuura, T. (2007). "Electrospun nanofibrous polysulfone membranes as pre-filters: Particulate removal," Journal of Membrane Science 289(1-2), 210-219. DOI: 10.1016/j.memsci.2006.11.056

Hassan, M. I., and Anke, K. (2020). "A review on electrospun polymeric nanofibers: Production parameters and potential applications," Polymer Testing 90, Article ID 106647. DOI: 10.1016/j.polymertesting.2020.106647

Hasolli, N., Park, Y. O., and Rhee, Y. W. (2013). "Filtration performance evaluation of depth filter media cartridges as function of layer structure and pleat count," Powder Technology 373(3), 24-31. DOI: 10.1016/j.powtec.2013.01.002

Japuntich, D. A., Stenhouse, J. I. T., and Liu, B. Y. H. (1997). "Effective pore diameter and monodisperse particle clogging of fibrous filters," Journal of Aerosol Science 28(1), 147-158. DOI: 10.1016/S0021-8502(96)00064-X 
Lee, K. M., Jo, Y. M., Lee, J. H., and Raper, J. A. (2008). “Assessment of surface and depth filters by filter quality," Powder Technology 185(2), 187-194. DOI: 10.1016/j.powtec.2007.10.013

Lim, C. H., Ryu, J., Choi, Y., Jeon, S. W., and Lee, W. K. (2020). "Understanding global PM2.5 concentrations and their drivers in recent decades (1998-2016)," Environment International 144(3), Article ID 106011. DOI: 10.1016/j.envint.2020.106011

Liang, C., Liang, Z., and Li, L. (2019). "Force analysis of unstable section of electrostatic spinning charged jet,” Journal of King Saud University - Science 31(4), 1528-1534. DOI: 10.1016/j.jksus.2019.02.008

Podgórski, A., Bałazy, A., and Gradoń, L. (2006). "Application of nanofibers to improve the filtration efficiency of the most penetrating aerosol particles in fibrous filters," Chemical Engineering Science 61(20), 6804-6815. DOI: 10.1016/j.ces.2006.07.022

Reneker, D. H., Yarin, A. L., and Zussman, E. (2007). "Electrospinning of nanofibers from polymer solutions and melts," Advances in Applied Mechanics 41, 43-195, 345-346. DOI: 10.1016/s0065-2156(07)41002-x

Spivak, A. F., Dzenis, Y. A., and Reneker, D. H. (2000). "A model of steady state jet in the electrospinning process," Mechanics Research Communications 27(1), 37-42. DOI: 10.1016/S0093-6413(00)00060-4

Srinivasan, G., and Reneker, D. H. (1995). "Structure and morphology of small-diameter electrospun aramid fibers," Polymer International 36(2), 195-201. DOI: 10.1002/pi.1995.210360210

Sun, Z., Min, T., Song, Q., Yu, J., Yun, L., Hu, J., and Wang, J. (2018). "Filtration performance of air filter paper containing kapok fibers against oil aerosols," Cellulose 25(4), 6719-6729. DOI: 10.1007/s10570-018-1989-7

Teo, W. E., and Ramakrishna, S. (2006). "A review on electrospinning design and nanofibre assemblies," Nanotechnology 17(14), R89-R106. DOI: 10.1088/09574484/17/14/R01

Tian, H., Yuan, L., Wang, J., Wu, H., Wang, H., Xiang, A., Ashok, B., and Rajulu, A. V. (2019). "Electrospinning of polyvinyl alcohol into crosslinked nanofibers: An approach to fabricate functional adsorbent for heavy metals," Journal of Hazardous Materials 378, Article ID 120751. DOI: 10.1016/j.jhazmat.2019.120751

Tucker, N., Stanger, J. J., Staiger, M. P., Razzaq, H., and Hofman, K. (2012). "The history of the science and technology of electrospinning from 1600 to 1995," Journal of Engineered Fibers and Fabrics 7(Suppl. 2), 63-73. DOI: $10.1177 / 155892501200702$ S10

Wang, C., Weng, Y., and Wang, L. (2021). "Effect of air quality on corporate environmental disclosure: The moderating role of institutional investors," Borsa Istanbul Review (In Press). DOI: 10.1016/j.bir.2021.02.005

Wang, G., Yu, D., Kelkar, A. D., and Zhang, L. (2017). "Electrospun nanofiber: Emerging reinforcing filler in polymer matrix composite materials," Progress in Polymer Science 75, 73-107. DOI: 10.1016/j.progpolymsci.2017.08.002

Wu, P., Fang, Z., Luo, H., Zheng, Z., Zhu, K., Yang, Y., and Zhou, X. (2021). "Comparative analysis of indoor air quality in green office buildings of varying star levels based on the grey method," Building and Environment 195, Article ID 107690. DOI: 10.1016/j.buildenv.2021.107690

Xie, X., Chen, Y., Wang, X., Xu, X., Shen, Y., Khan, A. R., Aldalbahi, A., Fetz, A. E., Bowlin, G. L., and El-Newehy, M. et al. (2020). "Electrospinning nanofiber 
scaffolds for soft and hard tissue regeneration," Journal of Materials Science \& Technology 59(15), 243-261. DOI: 10.1016/j.jmst.2020.04.037

Zdanowski, M., and Kędzia, J. (2007). "Research on the electrostatic properties of liquid dielectric mixtures," Journal of Electrostatics 65(8), 506-510. DOI: 10.1016/j.elstat.2006.11.006

Zhang, Z., Wu, Y., Wang, Z., Zhang, X., Zhao, Y., and Sun, L. (2017). "Electrospinning of Ag nanowires/polyvinyl alcohol hybrid nanofibers for their antibacterial properties," Materials Science and Engineering: C 78, 706-714. DOI: 10.1016/j.msec.2017.04.138

Zhao, W. (2006). "Particle size, uniformity, and mesostructure control of magnetic core/mesoporous silica shell nanocomposite spheres," Journal of Materials Research 21, 3080-3089. DOI: 10.1557/jmr.2006.0381

Article submitted: March 21, 2021; Peer review completed: May 16, 2021; Revised version received and accepted: May 25, 2021; Published: June 1, 2021.

DOI: 10.15376/biores.16.3.5220-5233 